\title{
Elastic and inelastic seismic response comparison of reinforced concrete buildings with normal resistance concrete and with high resistance concrete
}

\author{
J. A. Avila ${ }^{1,2} \&$ D. Rivera ${ }^{2}$ \\ ${ }^{1}$ Institute of Engineering, National University of Mexico (UNAM), \\ Mexico \\ ${ }^{2}$ Faculty of Engineering, National University of Mexico (UNAM), Mexico
}

\begin{abstract}
The elastic and inelastic seismic response of 3, 9, 17 and 25 levels of reinforced concrete buildings (offices), located in the soft soil of Mexico City, with normal resistance concrete $\left(\mathrm{f}_{\mathrm{c}}^{\prime}=250 \mathrm{~kg} / \mathrm{cm}^{2}\right)$ and with high resistance concrete $\left(\mathrm{f}_{\mathrm{c}}^{\prime}=700\right.$ $\mathrm{kg} / \mathrm{cm}^{2}$ ) are compared. The design with normal and high resistance concrete is made with the RDF-93 and RDF-04 codes respectively. The design results (transversal sections dimensions, vibration periods, lateral displacements, reinforcement steel, etc) are compared, after making a spectral modal dynamic analysis, as well as the non-linear responses (lateral displacements, global and local ductility demands, global distribution of plastic hinges, etc) from the step-by-step dynamic analysis with the SCT-EW record of the 1985 earthquakes.
\end{abstract}

\section{Introduction}

The elastic and inelastic behavior of 3, 9, 17 and 25 levels reinforced concrete buildings (offices) is compared; it is designed with the RDF-93 Code [1] for normal resistance concretes and with the RDF-2004 Code [2] for high resistance concretes. The service (the ratios of relative lateral displacement do not exceed of 0.012 times the story high) and failure (given resistances to satisfy the seismic behavior factor $\mathrm{Q}=3$ requirements) limit states are satisfied according to the Complementary Techniques Norms in both Codes. The structures are designed 
for the soft soil conditions (zone III for the RDF-93 and zone $\mathrm{III}_{\mathrm{b}}$ for the RDF2004) in Mexico City. For the design, the spectral modal dynamic seismic analysis is used, considering the elastic-lineal three-dimensional behavior; the vibration periods, maximum lateral displacements, ratios of relative lateral displacements to story high, shear forces, mechanics design elements (internal actions), and longitudinal and transversal reinforcements are compared. Based on these designs, the non-linear response is later determined making step-by-step dynamic analysis in time history, using the SCT-EW record representative soft soil and the bigger damages zone during the 1985 September earthquake in Mexico City. The maximum local ductility in beams and columns are calculated, as well as the global ductility and the tendencies that the failure mechanics develop. Finally, conclusions and recommendations to follow in the practical design of the kind of structures are presented, regarding both concrete resistance type.

\subsection{High resistance concretes}

Some of the high resistance concrete mechanical properties are different from the conventional concrete. Due to this some doubts about if the actual structural design procedures for conventional concretes are also used in high resistances ones. In the Techniques Norms of RDF-2004 it is allowed to use high resistance concretes with values of $\mathrm{f}_{\mathrm{c}}^{\prime}$ until $700 \mathrm{~kg} / \mathrm{cm}^{2}$, except the structures designed with a seismic behavior factor $\mathrm{Q}=4$ and members facing flexion-compression that take part of frames resisting more than $50 \%$ of the seismic actions and which design axial load $\left(\mathrm{P}_{\mathrm{u}}\right)$ is bigger than $0.2 \mathrm{P}_{\mathrm{RO}}$, where $\mathrm{P}_{\mathrm{RO}}$ is the design resistant axial load; in this cases only concretes with $\mathrm{f}_{\mathrm{c}}^{\prime}$ until $550 \mathrm{~kg} / \mathrm{cm}^{2}(55 \mathrm{MPa})$ can be used. This Norms propose to use the following equation in order to obtain the elasticity modulus in high resistance concretes:

$$
E_{c}=7700\left(f^{\prime}\right)^{1 / 2}+163000\left(\mathrm{~kg} / \mathrm{cm}^{2}\right) \text { or } \mathrm{Ec}=2400\left(\mathrm{f}_{\mathrm{c}}{ }^{\prime}\right)^{1 / 2}+16300(\mathrm{MPa})
$$

Fig. 1 shows some curves stress-deformation for different values of $\mathrm{f}^{\prime}$. Some of the main parameters to consider in high resistance concretes are the following: a) workability, b) permeability, c) volumetric changes, d) durability in useful life. For design consideration purposes, flexion and axial load, many of the design procedures used for the conventional concretes have been applied and in most of the cases good results have been obtained.

The maximum unitary deformation value in the concrete $\varepsilon_{\mathrm{cu}}=0.003$ adopted in conventional concrete design, has also adequate, but less conservative for high resistance concretes. The equivalent rectangular block of compression stress is proposed, but its application in high resistance concrete members facing to flexion and flexure-compression has been questioned because in the Norms a superior limit of $\mathrm{f}^{\prime}{ }_{\mathrm{c}}$ from which such block is invalid has not been specified. The concrete ductility is going to diminish as long as the ${f^{\prime}}_{c}$ value increases. The transversal reinforcement presence increases the resistance and ductility of a high resistance concrete column, but in less magnitude than the normal concrete due 
to the tendency of lateral deformations to be considerably smaller, which produces a less effective confinement. If the axial load is bigger than $0.40 \mathrm{P}_{\mathrm{RO}}$ the use of high resistance steel for the transversal reinforcement is recommended, trying to avoid the reinforcement congestion in the structure nodes. The confinement level is directly proportional to the concrete resistance and does not consider the axial load level in the structural element. Therefore in members where the $\mathrm{f}^{\prime}{ }_{\mathrm{c}}$ resistance is high, we have a high transversal steel percentage and in consequence construction problems.

Despite of the augmentation in concrete costs as its resistance increases, the total cost of the structure will be less, because the concrete resistance augmentation causes an important reduction in the structural elements dimensions as well as in the reinforcement areas.

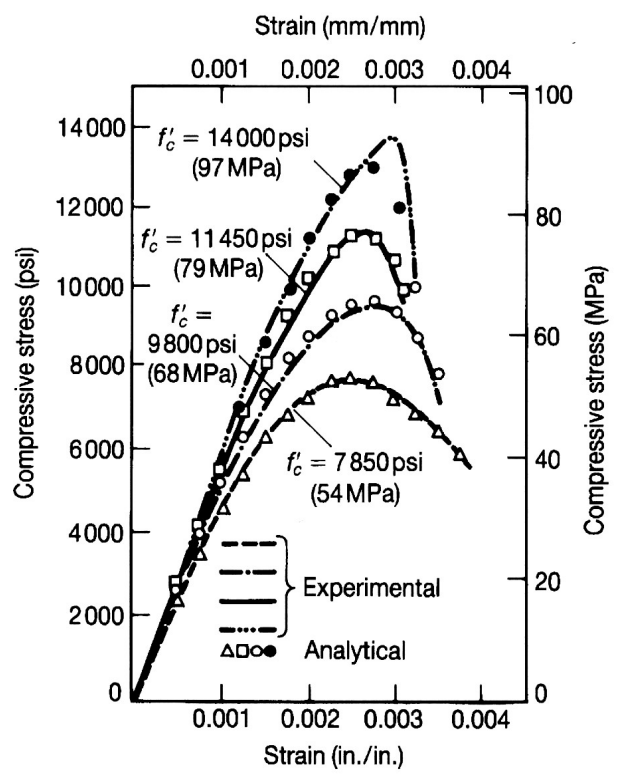

Figure 1: Curves stress-deformation for several concretes.

\section{Structures description}

Two kinds of structures are considered: A case (normal concrete with $\mathrm{f}^{\prime}{ }_{\mathrm{c}}=250$ $\mathrm{kg} / \mathrm{cm}^{2}$ and $\mathrm{B}$ case (high resistance concrete with $\mathrm{f}^{\prime}{ }_{\mathrm{c}}=700 \mathrm{~kg} / \mathrm{cm}^{2}$ ). The elasticity modulus for both cases is $E_{c}=14000\left(f^{\prime}{ }_{c}\right)^{1 / 2}\left(221,359 \mathrm{~kg} / \mathrm{cm}^{2}\right)$ and $E_{c}=7700$ $\left(\mathrm{f}^{\prime}{ }_{\mathrm{c}}\right)^{1 / 2}+163000\left(366,723 \mathrm{~kg} / \mathrm{cm}^{2}\right)$, respectively. The concrete is class 1 with volumetric weight $\gamma_{\mathrm{c}}=2400 \mathrm{~kg} / \mathrm{cm}^{2}$ and $v=0.2$; the reinforced steel used has a yield stress $\mathrm{f}_{\mathrm{y}}=4200 \mathrm{~kg} / \mathrm{cm}^{2}$.

Figs. 2 and 3 show the type plant and transversal cuts of 3 and 9 level buildings; fig. 4 shows the type plant of 17 and 25 level buildings. Also, the 
structural characteristics of each building are presented. The floor system is concrete slab type of $10 \mathrm{~cm}$ thickness.

\subsection{Design criteria}

The gravitational loads effects and those of second order (P- $\Delta)$ are included in the analysis. For A case the seismic design spectra of soft soil is considered (Zone III) of the RDF-93 and the Zone III $_{\mathrm{b}}$ spectra of the RDF-2004 for the B case, considering the seismic behavior factor $Q=3$ (see fig. 5).

The reinforcement steel areas of the structural elements design (beams and columns) is made with the last mechanical elements obtained from the structural analysis for the critical load combination; it is according to the general requirements and ductile frames of the Concrete Norms. These designs include the load factor and the resistance reduction factor.
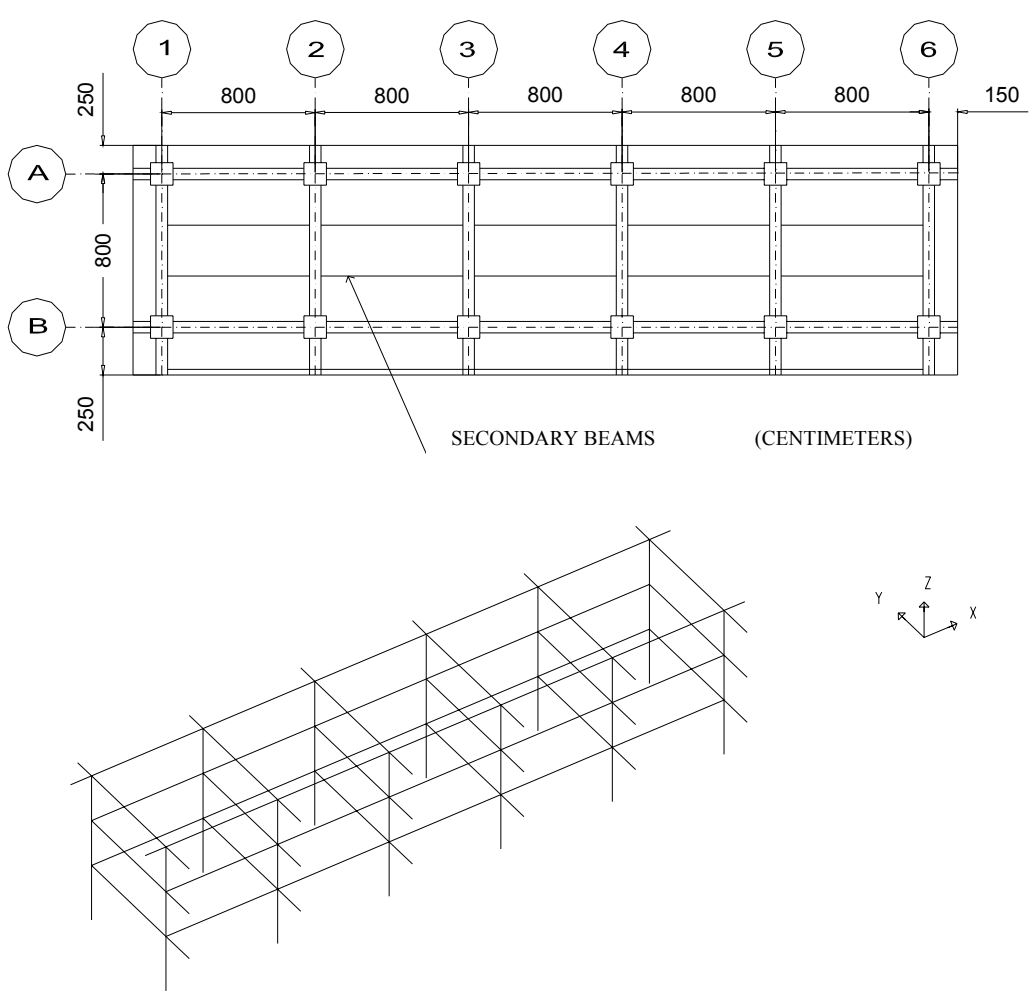

Figure 2: $\quad$ Type plant and three-dimensional 3 level model. 
High Performance Structures and Materials III 443
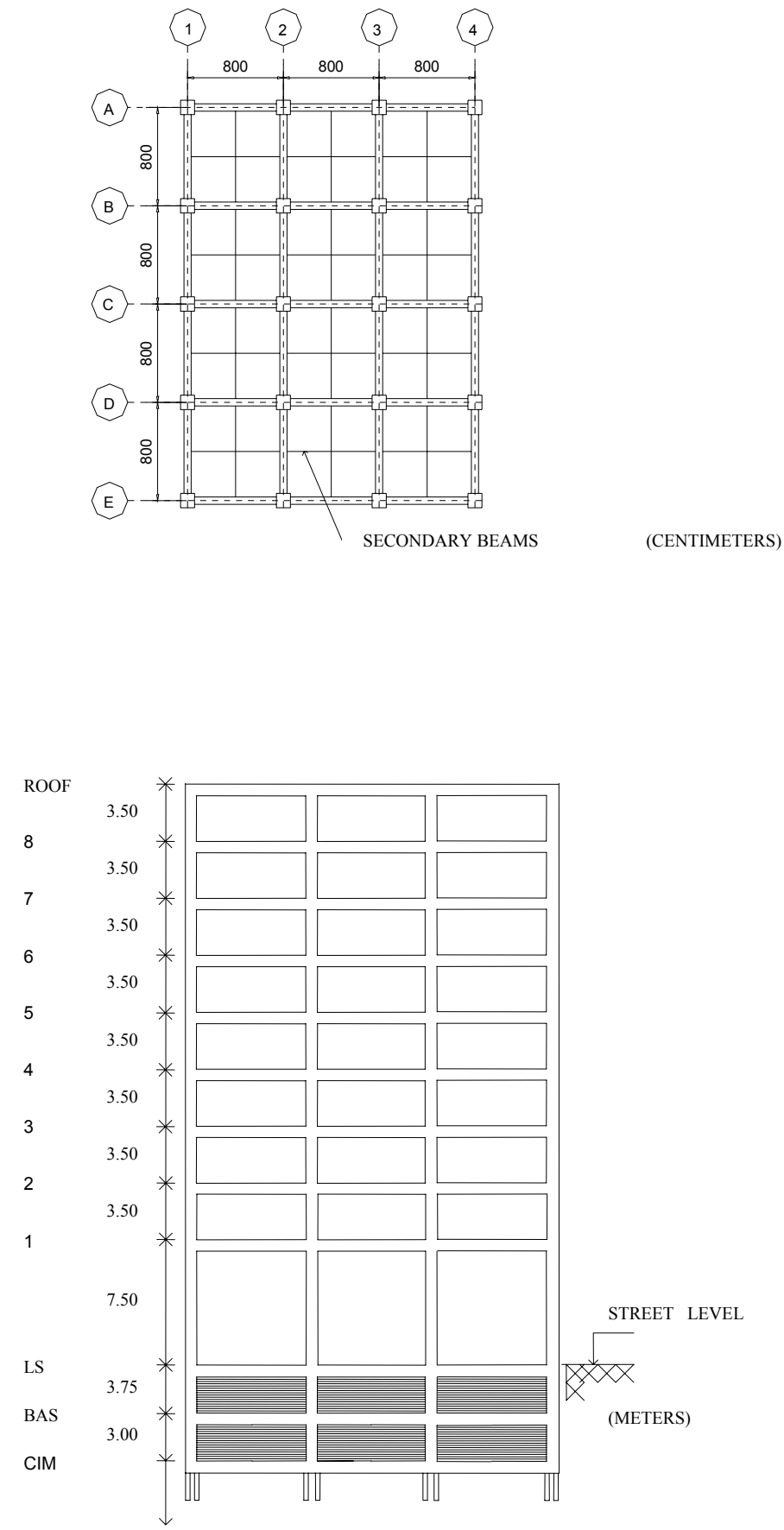

Figure 3: $\quad$ Type plant and transversal cut, 9 level model. 


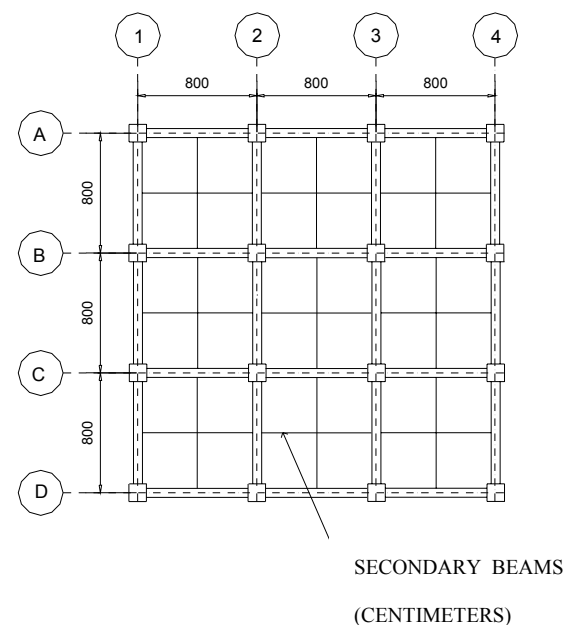

Figure 4: $\quad$ Type plant, 17 and 25 level models.

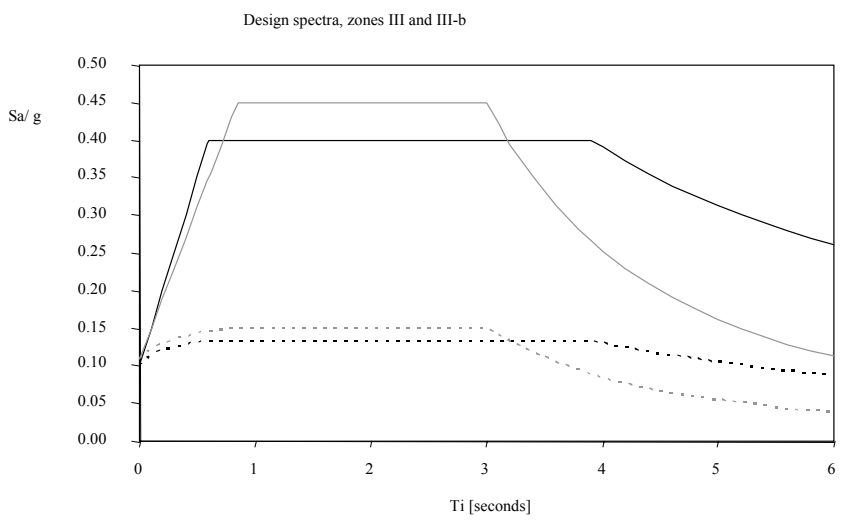

Figure 5: Design spectra RDF-93 and RDF-2004, $\mathrm{Q}=1$ and $\mathrm{Q}=3$.

\section{Design elastic responses}

\subsection{Transversal sections and reinforcement areas}

The dimensions of the structural elements of the transversal sections in B case are smaller. This reduction is more important in columns, so that the resistance increase to compression in the concrete has a bigger influence in the behaviour of elements with high axial loads. In the majority of B case elements, the required reinforcement areas were smaller; only the some external axes columns, the reinforcement result similar in both cases. 


\subsection{Fundamental periods of vibration}

Table 1 compares the fundamental periods of vibration of analysed A and B case buildings. The A case structures tend to be less rigid.

Table 1: $\quad$ Fundamental periods of vibration comparison 3, 9, 17 and 25 level models (A and B cases).

\begin{tabular}{|c|c|c|c|c|}
\hline \multirow{2}{*}{ MODEL } & \multirow{2}{*}{ CASE } & \multicolumn{3}{|c|}{ Fundamental period of vibration [seconds] } \\
\cline { 3 - 5 } & & $\mathrm{X}$ & $\mathrm{Y}$ & $\theta$ \\
\hline \multirow{2}{*}{3} & $\mathrm{~A}$ & 0.80 & 0.80 & 0.69 \\
\cline { 2 - 5 } & $\mathrm{B}$ & 0.70 & 0.74 & 0.63 \\
\hline \multirow{2}{*}{9} & $\mathrm{~A}$ & 1.49 & 1.45 & 1.07 \\
\cline { 2 - 5 } & $\mathrm{B}$ & 1.44 & 1.41 & 1.09 \\
\hline \multirow{2}{*}{17} & $\mathrm{~A}$ & 1.91 & 1.91 & 1.38 \\
\cline { 2 - 5 } & $\mathrm{B}$ & 1.84 & 1.84 & 1.42 \\
\hline \multirow{2}{*}{25} & $\mathrm{~A}$ & 2.10 & 2.10 & 1.39 \\
\cline { 2 - 5 } & $\mathrm{B}$ & 1.88 & 1.88 & 1.38 \\
\hline
\end{tabular}

Fig. 6 has the September $19^{\text {th }} 1985$ earthquake SCT-EW accelerogram, used later in the inelastic analysis. Fig. 7 shows the elastic and inelastic response spectra of this record $(\varphi=5 \%)$ and of RDF-2004, as well as the fundamental periods of vibration location (X direction) of all the structures, $\mathrm{A}$ and $\mathrm{B}$ cases. When the level number increases, the difference between both cases tends to be bigger.

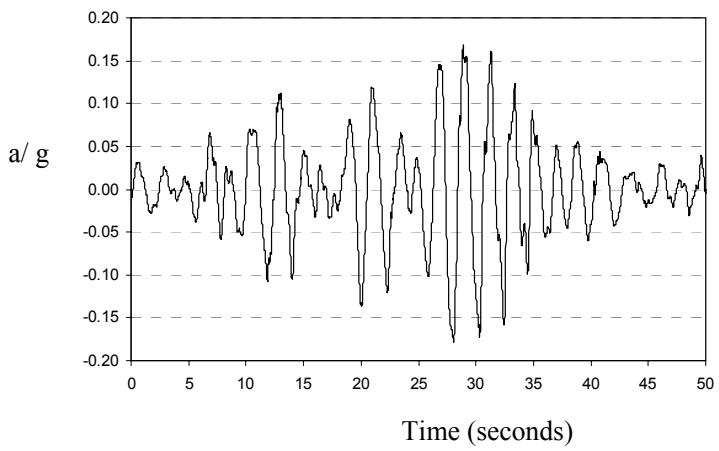

Figure 6: September $19^{\text {th }} 1985$ earthquake SCT-EW accelerogram.

\subsection{Total maximum lateral displacements}

In both design cases very similar responses are presented, so that, if the A case structures result less rigid than those of $\mathrm{B}$ case is because they were designed with the RDF-93 with a maximum spectral level of 0.40 , in comparison with the 0.45 value for the RDF-2004.

\subsection{Ratios of relative lateral displacement to story high (drifts)}

The 3 and 9 level buildings present less drifts because in these the resistance conditions ruled, therefore it was necessary to increase the dimensions in some 
of the structural elements regarding to the required in the service limit state, checking not to exceed the 0.012 permissible limit.
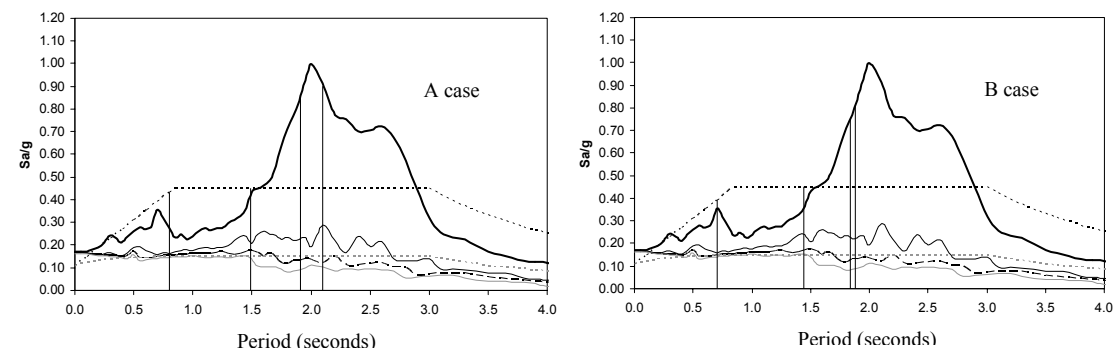

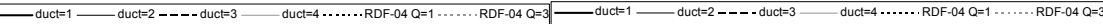

Figure 7: Fundamental periods of vibration location regarding the design spectra of the RDF-2004 and of response spectra SCT-EW, A and $\mathrm{B}$ cases.

\section{Inelastic step-by-step seismic analysis responses}

\subsection{Maximum lateral displacements and global ductility demands}

Generally the inelastic response was less than the elastic, especially in high buildings (17 and 25 levels), because in these there was bigger energy dissipation; in the 3 level building both responses were very similar. Table 2 presents the global ductility maximum demands $\left(\mu_{\mathrm{G}}\right)$ developed in each structure; excepting the 3 level building, the $m_{G}$ values are bigger in A case buildings with a bigger energy dissipation than those in $\mathrm{B}$ case; it is important to notice that in any case the $\mu_{\mathrm{G}}$ was bigger than the design value of $\mathrm{Q}=3$.

\subsection{Ratios of relative lateral displacement to story high (drifts)}

The inelastic response diminishes considerably from the elastic, until reaching permissible level values; the A case responses tend to be bigger.

Table 2: $\quad$ Global ductility demands $\left(\mathrm{m}_{\mathrm{G}}\right)$ 3, 9, 17 and 25 level models (A and B cases).

\begin{tabular}{|c|c|c|c|c|c|c|c|}
\hline \multirow{3}{*}{ MODEL } & \multirow{2}{*}{ AXE } & \multicolumn{6}{|c|}{ Global ductility demand $\left(\mu_{\mathrm{G}}\right)$} \\
\cline { 3 - 8 } & & \multicolumn{3}{|c|}{ A case } & \multicolumn{3}{c|}{ B case } \\
\cline { 3 - 8 } & $\Delta_{\max }[\mathrm{cm}]$ & $\Delta_{\mathrm{y}}[\mathrm{cm}]$ & $\mu_{\mathrm{G}}$ & $\Delta_{\max }[\mathrm{cm}]$ & $\Delta_{\mathrm{y}}[\mathrm{cm}]$ & $\mu_{\mathrm{G}}$ \\
\hline \multirow{2}{*}{3} & $\mathrm{~A}$ & 5.48 & 4.82 & 1.14 & 5.27 & 3.74 & 1.41 \\
\hline & 3 & 5.64 & 5.42 & 1.04 & 5.90 & 3.15 & 1.91 \\
\hline \multirow{2}{*}{9} & $\mathrm{~A}$ & 41.12 & 17.40 & 2.36 & 32.30 & 13.80 & 2.34 \\
\cline { 2 - 8 } & $\mathrm{C}$ & 43.06 & 16.70 & 2.58 & 29.10 & 14.90 & 1.96 \\
\hline \multirow{2}{*}{17} & $\mathrm{~A}$ & 51.00 & 22.40 & 2.28 & 39.88 & 19.85 & 2.01 \\
\cline { 2 - 8 } & $\mathrm{B}$ & 48.98 & 18.50 & 2.65 & 38.36 & 18.84 & 2.04 \\
\hline \multirow{2}{*}{25} & $\mathrm{~A}$ & 77.26 & 29.30 & 2.64 & 45.18 & 20.61 & 2.19 \\
\cline { 2 - 8 } & $\mathrm{B}$ & 76.73 & 30.70 & 2.50 & 44.10 & 28.56 & 1.54 \\
\hline
\end{tabular}




\subsection{Ratios of basal shear force-roof lateral displacement}

Table 3 compares the maximum values of the roof lateral displacement and the basal shear force, elastic and inelastic behavior, of the analyzed structures (3, 9, 17 and 25 levels), A and B cases. Excepting the 3 level building, the ratios of basal shear force-roof lateral displacement result bigger in B case.

Table 3: $\quad$ Ratios of basal shear force-roof lateral displacement.

\begin{tabular}{|c|c|c|c|c|c|c|}
\hline \multirow{3}{*}{ MODEL } & \multirow{3}{*}{ AXE } & \multirow{3}{*}{ CASE } & \multicolumn{4}{|c|}{$\begin{array}{l}\text { Roof lateral displacements and } \\
\text { maximum basal shear forces }\end{array}$} \\
\hline & & & \multicolumn{2}{|c|}{ A case } & \multicolumn{2}{|c|}{ B case } \\
\hline & & & $\Delta[\mathrm{cm}]$ & $\mathrm{V}[\mathrm{t}]$ & $\Delta[\mathrm{cm}]$ & $\mathrm{V}[\mathrm{t}]$ \\
\hline \multirow{4}{*}{3} & \multirow{2}{*}{ A } & Elas. & 5.47 & 161 & 5.68 & 203 \\
\hline & & Inel. & 5.45 & 156 & 5.27 & 164 \\
\hline & \multirow{2}{*}{3} & Elas. & 5.61 & 60 & 5.89 & 56 \\
\hline & & Inel. & 5.64 & 57 & 5.90 & 52 \\
\hline \multirow{4}{*}{9} & \multirow{2}{*}{ A } & Elas. & 49.30 & 859 & 27.90 & 525 \\
\hline & & Inel. & 41.12 & 382 & 30.93 & 331 \\
\hline & \multirow{2}{*}{$\mathrm{C}$} & Elas. & 44.80 & 706 & 28.11 & 518 \\
\hline & & Inel. & 43.05 & 406 & 29.11 & 329 \\
\hline \multirow{4}{*}{17} & \multirow{2}{*}{ A } & Elas. & 149.00 & 2710 & 93.14 & 1792 \\
\hline & & Inel. & 51.00 & 582 & 44.81 & 424 \\
\hline & \multirow{2}{*}{ B } & Elas. & 148.00 & 2610 & 92.00 & 1757 \\
\hline & & Inel. & 48.97 & 566 & 46.58 & 407 \\
\hline \multirow{4}{*}{25} & \multirow{2}{*}{ A } & Elas. & 143.00 & 3920 & 107.84 & 3277 \\
\hline & & Inel. & 77.26 & 1261 & 55.56 & 921 \\
\hline & \multirow{2}{*}{ B } & Elás. & 142.00 & 3830 & 107.57 & 3229 \\
\hline & & Inel. & 76.73 & 1269 & 55.39 & 9910 \\
\hline
\end{tabular}
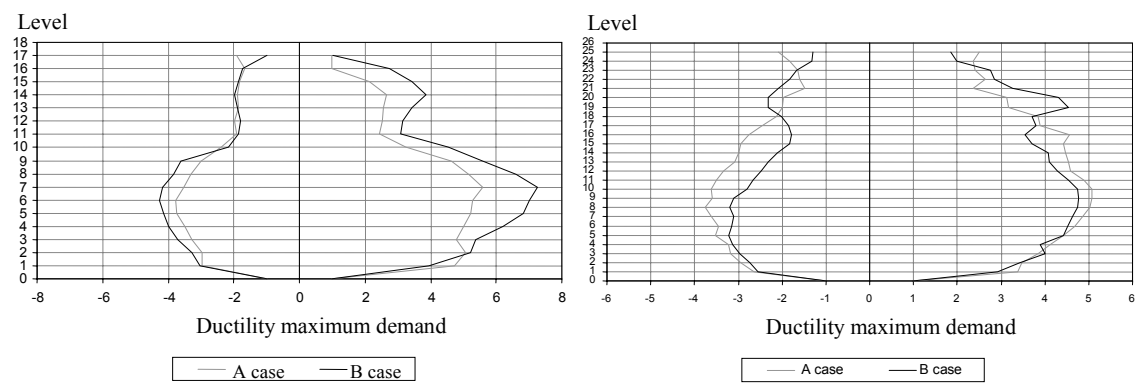

Figure 8: Local ductility maximum demands $\left(\mu_{\mathrm{L}}\right)$ in beams, 17 and 25 level buildings, A and B cases.

\subsection{Local ductility maximum demands $\left(\mu_{\mathrm{L}}\right)$ in beams and columns and global distribution of plastic hinges}

The 3 level building does not present yield in columns. The beams in all buildings have very similar responses, independently of the case type; the beams maximum demands are rarely bigger in A case. The $\mu_{\mathrm{L}}$ maximum values in beams as in columns are obtained in the 9 level building, but inside the admissible limits from the practical point of view. Fig. 8 compares the local 
ductility maximum demands developed in the beams of the 17 and 25 level buildings central axes, A and B cases, for illustrative purposes.

In all buildings, $\mathrm{A}$ and $\mathrm{B}$ cases, global distribution of plastic hinges presents a general tendency towards the failure mechanism known as "strong column-weak beam" type. This means that plastic hinges are in the most part of the beams and only in some columns, which is according to the actual design philosophy of RDF-93 and RDF-2004 codes.

\section{Conclusions}

Use of high resistance concretes $\left(\mathrm{f}_{\mathrm{c}}^{\prime}>400 \mathrm{~kg} / \mathrm{cm}^{2}\right)$ in reinforced concrete columns improves in a great deal its axial load capacity; therefore in front of actions where compression high loads predominate its behavior is very adequate; nevertheless, in front of less magnitude loads or even tensions its use results almost no efficient because the resistance is given mainly by the reinforcement steel. The most part of the energy dissipation is in the beams, no matter what type of structure it is. The A case structures present a bigger amplitude in the hysteretic cycles of the ratios of basal shear force-roof lateral displacement, with bigger dissipated energy amount for inelastic deformations. The maximum values of local ductility demands are found inside the permissible by the RDF-93 and RDF-2004. The inelastic response is considerably reduced regarding to the elastic one, except in the 3 level building, where the elastic and inelastic responses tend to be practically the same. In every analyzed case, reviewing the shear forces history, the corresponding resistance is never reached; this is, there is always a resistance reservation, which is bigger in B case buildings, so that for this case a bigger quantity of transversal reinforcement by confinement was required because the design conditions for transversal reinforcement must be more strict as the $\mathrm{f}^{\prime}{ }_{\mathrm{c}}$ value increases.

\section{References}

[1] Diario Oficial de la Federación, Reglamento de Construcciones del Distrito Federal, 1993.

[2] Gaceta Oficial del Gobierno de la ciudad de México, Reglamento de Construcciones del Distrito Federal, 2004. 